\title{
Editorial
}

\section{Cardiomyopathies in Indian Women}

\author{
Thiagarajan Sairam¹ Perundurai S. Dhandapany ${ }^{1}$ \\ ${ }^{1}$ Institute for Stem Cell Science and Regenerative Medicine \\ (InStem), Centre for Cardiovascular Biology and Disease, \\ GKVK-Post, Bangalore, Karnataka, India \\ Ind J Car Dis Wom 2019;4:65
}

Cardiomyopathy is a disease of cardiac muscle arising from mutations in sarcomeric protein genes, and majorly classified into dilated cardiomyopathy (DCM) and hypertrophic cardiomyopathy ( $\mathrm{HCM})$ forms based on their distinct pattern of ventricular remodeling. Cardiovascular disease mortality was estimated to be higher in Indian population than the global average. ${ }^{1}$ Interestingly, recent evidence suggests that pathogenesis and prognosis of both DCM and HCM are highly influenced by sex. ${ }^{2}$ Clinically, women with HCM have worse survival than men and present at an advanced age with severe symptoms. ${ }^{3}$ These observed differences between men and women may be due to additional genetic alterations. ${ }^{2}$

Moreover, genetic defects have a vital role in cardiomyopathy, especially mutations in $\beta$-myosin heavy chain gene; contraction. So far, a large number of mutations have been reported in the $\beta$-myosin heavy chain that predominantly lead to HCM; however, fewer mutations cause DCM. Previously, in Indian HCM and DCM patients, $\beta$-myosin heavy chain gene was screened for mutations and identified novel variants such as p.Gly716Arg, p.Gly377Ser, p.Gly377Arg, and p.Arg787His ${ }^{4,5}$ that are highly associated with cardiomyopathy. However, no studies so far were done in India on sex-specific difference in women cardiomyopathy cases.

In this issue, Rani et al (2019) ${ }^{6}$ has screened exons of $\beta$-myosin heavy chain gene from an Indian women cohort with 33 HCM and 48 DCM cases. Major significance of this work is that the authors specifically screened female cohort, which might help in finding, if any, gender-specific pathogenic mutations in $\beta$-myosin heavy chain gene causing HCM. The authors identified a novel mutation Val431Met that is exclusively present in women cardiomyopathy patients but not in healthy controls.

Further, to investigate the functional significance of the mutant Met431, authors used the in silico protein homology model approach. These results suggest that the mutant Met431 found to be buried in the hydrophobic core consequently leads to aberrant hydrophobic interaction with an essential sarcomeric protein involves in heart muscle

Leu 352. Thus, this structural deviation may cause cardiac remodeling and cardiomyopathy. However, further functional studies will help in elucidating the exact pathogenic mechanisms. Apart from missense mutation Val431Met, they have also identified two intronic variations and six silent mutations. In one DCM patient, in addition to Val431Met, they have found three more variants (A423T, synonymous F244 [homozygous], and one splice site IVS7-1G) and the variant A423T is also present in healthy controls. Although, authors did not compare mutations in men to determine the predominance of female-specific mutations for cardiomyopathy, this work is a prelude for future studies to understand sexual dimorphism in cardiovascular diseases.

\section{Conflict of Interest}

None declared.

\section{References}

1 Prabhakaran D, Jeemon P, Roy A. Cardiovascular diseases in India: current epidemiology and future directions. Circulation 2016;133(16):1605-1620

2 Fairweather D, Cooper LT Jr, Blauwet LA. Sex and gender differences in myocarditis and dilated cardiomyopathy. Curr Probl Cardiol 2013;38(1):7-46

3 Geske JB, Ong KC, Siontis KC, et al. Women with hypertrophic cardiomyopathy have worse survival. Eur Heart J 2017;38(46):3434-3440

4 Rai TS, Ahmad S, Bahl A, et al. Genotype phenotype correlations of cardiac beta-myosin heavy chain mutations in Indian patients with hypertrophic and dilated cardiomyopathy. Mol Cell Biochem 2009;321(1-2):189-196s11010-008-99

5 Boda U, Vadapalli S, Calambur N, Nallari P. Novel mutations in beta-myosin heavy chain, actin and troponin-I genes associated with dilated cardiomyopathy in Indian population. J Genet 2009;88(3):373-377

6 Rani DS, Nallari P, Narasimhan C, et.al. Novel variations in $\beta$-myosin heavy chain gene ( $\beta$-MYH7) and its association in South Indian women with cardiomyopathies. Women Cardiol Rel Sci 2009; doi:10.1055/s-0039-1694829
C)2019 Women in Cardiology and Related Sciences
License terms

(우(1) $\odot \circledast$
Address for correspondence Perundurai S. Dhandapany, PhD, Institute for Stem Cell Science and Regenerative Medicine (InStem), Centre for Cardiovascular Biology and Disease, GKVK-Post, Bangalore, Karnataka 560065, India (e-mail: dhan@instem.res.in). published online August 29, 2019
DOI https://doi.org/ 10.1055/s-0039-1697768 